\title{
Efficacy of Educational Interventions Targeting Primary Care Providers' Practice Behaviors: an Overview of Published Systematic Reviews
}

\author{
Woosung Sohn, DDS, PhD, DrPH; Amid I. Ismail, BDS, MPH, DrPH; Marisol Tellez, BDS, MPH
}

\begin{abstract}
Objectives: Primary care providers (e.g., family physicians, pediatricians, registered nurses, physician assistants, and nurse practitioners) could play a pivotal role in the provision of preventive services, especially for very young children (younger than 3 years old) and population groups with limited access to dental care. Given the current problems with access to dental care among low-income Americans, we contend there is a need to involve nondental primary health care providers in screening for and preventing oral health problems. The objective of this overview is to present findings from systematic reviews on the efficacy of continuing medical education, printed educational material, academic outreach, reminders, and local opinion leaders on the adoption of new knowledge and practices by primary care providers. Methods: A search was conducted using the Cochrane Library and MEDLINE. The search aimed to locate systematic reviews published between January 1988 and March 2003. Two researchers independently extracted data and assessed study quality using a modified version of the QUOROM statement. Results: Eleven systematic reviews were included in this overview. The evidence from the included systematic reviews showed that formal continuing medical education (CME) and distributing educational materials did not effectively change primary care providers' behaviors. There are effective interventions available to increase knowledge and change behaviors of primary care providers, such as small group discussion, interactive workshops, educational outreach visits, and reminders. Conclusion: There is a limited knowledge base on the efficacy of the selected interventions on oral health screening by primary care providers. Considering the potential role of primary care providers in improving oral health of underserved populations, this research area should receive more attention. [J Public Health Dent 2004;64(3):164-72]
\end{abstract}

Key Words: systematic review, educational intervention, primary care providers, oral health screening.

While oral health status of American children and young adults has improved significantly during the past three decades, the burden of oral diseases is still high among underserved low-income population groups who lack access to adequate dental care and have higher exposure than other Americans to risk factors associated with poor oral health (1). The Third National Health and Nutrition Examination Survey (NHANES III) found that about one-third of preschoolers from low-income families had at least one primary tooth with untreated de- cay, whereas only 12 percent or fewer children from higher-income families had such cavities (2).

Among other reasons, infrequent dental visits due to limited access to dental care services are attributed to the oral health disparities among children $(3,4)$. Although publicly funded programs such as Medicaid have succeeded dramatically in providing regular medical care to children from low-income families, Medicaid's record of ensuring regular access to dentists and providing effective dental care is less successful (1). Fewer than one in five Medicaid-covered children received a single preventive dental visit between 1992 and 1993, according to the US inspector general (5). The study indicated that three-fourths of states provided preventive services to fewer than 30 percent of eligible children, and no state provided preventive dental care to more than 50 percent of all eligible children. A 1998 survey of state Medicaid programs by the National Conference of State Legislatures (6) reported that, on average, only 16 percent of dentists in the 35 responding states participated actively in Medicaid.

Given the current problems with access to dental care among low-income Americans, we contend there is a need to involve nondental primary care providers (e.g., family physicians, pediatricians, registered nurses, physician assistants, and nurse practitioners) to play a role in promoting oral health by providing advice and referring patients for dental care. In areas with severe shortage of dentists, primary care providers (primary care providers) may provide preventive screening in collaboration with organized dental groups or associations. There are currently initiatives in some states, such as North Carolina and Washington, to train primary care providers to provide early oral health screening and preventive care for lowincome children. Primary care providers could play a pivotal role in the provision of preventive services, especially for very young children (younger than 3 years old) and population groups with limited access to dental care $(7,8)$.

Currently, there is limited information on adoption levels of early screening and prevention of oral health problems by primary care providers. There

Send correspondence and reprint requests to Dr. Woosung Sohn, Department CRS\&E, School of Dentistry D2516, University of Michigan, 1011 N. University, Ann Arbor, MI 48109-1078. E-mail: woosung@umich.edu. Dr. Ismail is with the School of Dentistry and Dr. Tellez is a doctoral student in the School of Public Health, both at the University of Michigan. This study was partially supported by a grant from NIDCR/NIH/USPHS (DE014401-03). Manuscript received: 6/17/03; returned to authors for revision: 7/9/03; final version accepted for publication: $11 / 25 / 03$. 
are many barriers to engaging primary care providers in promoting oral health in their practices and no concerted plan exists to translate and disseminate information on oral health to primary care providers. Recent surveys targeting physicians have consistently reported that primary care physicians (family physicians and pediatricians) are well aware of the importance of their role in promoting oral health and are willing to participate in programs to achieve this goal, but they have limited knowledge of issues related to oral health and new fluoride supplementation guidelines (7; unpublished report, copies available from the authors). There is a need to investigate methods of translating and disseminating information on oral health to primary care providers to modify their practice behaviors to include oral health screening and prevention.

The objective of this paper is to present findings from systematic reviews on the efficacy of educational interventions in the form of continuing medical education and dissemination of educational materials, academic outreach, reminders and local opinion leaders, on the adoption of new knowledge and practices by primary care providers. These four interventions were chosen as a focus of this overview because they represent the methods that are widely used to disseminate information to primary care providers. These methods can also be used practically by dental public health professionals in programs that aim to involve primary care providers in early screening and prevention of oral health problems in low-income Americans.

\section{Methods}

Interventions. The definitions of the interventions included in this overview are: (modified from the definitions by Oxman et al.) (9):

Educational Materials: Transferring information through disseminating educational materials such as printed recommendations for clinical care including clinical practice guidelines, audiovisual materials, and electronic publications.

Formal Continuing Medical Education: Education provided in the forms of conferences, lectures, workshops, or educational meetings.

Educational Outreach Visits (Aca- demic Detailing): Presentation by a trained person who meets with providers in their practices to provide information in an interactive format. The information given may include feedback on the provider's performance.

Local Opinion Leaders: Distribution of educational materials by providers who are nominated or considered by their colleagues as "educationally influential."

Reminders: Any intervention (manual or computerized) that prompts the health care providers to perform a clinical action. Examples include concurrent or intervisit reminders to professionals about desired actions such as screening or other preventive services, enhanced laboratory reports, or administrative support (e.g., followup appointment system or stickers on chart). Computerized reminder system was not included in this review.

Search Strategy. A search for relevant systematic reviews was conducted using the Cochrane Library and MEDLINE. The search aimed to locate systematic reviews published between January 1988 and March 2003. The search terms used were the following: "continuing medical education," "CME," "educational material," "practice guideline," "opinion leader," "consensus process," "outreach visit," "academic detailing," "reminder." These terms were used in combination with "primary care provider," "nurse," "physician," "health care provider," "medical practice," "primary health care," "family practice," "physician's practice patterns," "mass screening," and "professional practice." A filter that included the following terms was used: "metaanalysis," "quantitative review/overview," "systematic review/overview," "methodologic review/overview," "medline," and "pooled." Letters, editorials, or comments were excluded. The reference list of the systematic reviews identified by the search were screened to locate additional reviews. Decisions on inclusion/exclusion of each review were made separately by two of the authors (WS and $\mathrm{AI}$ ); any disagreements were revolved by consensus.

Inclusion Criteria. For this overview, only completed systematic reviews of interventions that aimed to promote adoption of new practice behaviors by health care providers were included. The inclusion criteria were:

Interventions: Included reviews focused on the efficacy of at least one of the following interventions: formal continuing medical education including dissemination of educational materials, outreach visits (academic detailing), reminders, and local opinion leaders on health care professionals' adoption of new practices and practice behaviors. This overview focused on the efficacy of single interventions. Therefore, systematic reviews that reported on the efficacy of combinations of these interventions were included only if information on the efficacy of each single intervention was described.

Outcome Measures: There was a wide range of outcome measures described in the systematic reviews located by the search. While our primary outcome measures of interest were primary care providers' adoption of new procedures or their knowledge level, we included reviews that have described a broad range of outcomes (e.g., adoption of new preventive practices, improvement in preventive practices, clinical management of medical conditions, and prescribing practice). However, reviews that focused solely on the efficacy of interventions on reducing cost of prescription were excluded. Reviews that solely focused on patient outcomes rather than primary care providers' performance or knowledge also were not included in this overview.

Participants: Main participants of each systematic review were primary care providers including physicians, nurses, nurse practitioners, and physician assistants.

Quality of Reporting: Only reviews that clearly reported the search terms, databases searched, and explicit inclusion/exclusion criteria were selected.

Primary Study Design: We selected reviews that included randomized controlled trials (RCT), controlled trials with at least two arms (CCT), or controlled before and after studies (CBA) and interrupted time series analyses (ITA).

Language: We selected reviews reported in English.

Multiple Publication: In case a systematic review was published with multiple updates, only the most recent version was included.

Data Abstraction: Abstraction form included information on interven- 
tions, databases searched, designs of included studies, targeted professional groups, results of each included systematic review, number of studies included, their findings, and the authors' conclusions. Data abstraction was performed by two authors (WS and MT) and disagreements were resolved by consensus.

The quality of included systematic reviews was evaluated using the QUOROM checklist of standards for reporting of systematic reviews (10). A total of 17 items was evaluated and a quantitative score was generated based on the number of items that fulfilled the criteria. From this quantitative score, we assigned one of the following ratings of the scientific quality to each systematic review: (1) minimal flaws (15 or more items fulfilled), (2) minor flaws (13-14 items fulfilled), (3) major flaws (11-12 items fulfilled), and (4) extensive flaws (10 or fewer items fulfilled).

\section{Results}

A search of the Cochrane Library yielded 77 systematic reviews. Additionally, a MEDLINE search yielded 119 reviews. We located one additional systematic review through hand search. As a total we located 197 systematic reviews. By screening titles and abstracts, we selected 24 systematic reviews that focused on the 5 interventions of interest targeting health care professionals and their practice behaviors. From the 24 systematic reviews, we selected 11 reviews that met the inclusion criteria (Table 1). The remaining 13 reviews were excluded mainly because the efficacy of a single intervention could not be assessed separately, or because a review did not include any outcome measures related to primary care provider performance (Table 2). The quality of reporting of the included systematic reviews was generally high. The quality score based on the QUOROM check list ranged from minor to minimal flaws, indicating they fulfilled at least 13 items out of 17 in the list (Table 3). Efficacy of each single intervention is briefly summarized in Table 4.

Dissemination of Educational Materials. Four systematic reviews that met our inclusion criteria described the efficacy of disseminating educational materials or clinical guidelines. Davis et al. (11) reported that seven out of 11 studies that compared educa-

TABLE 1

List of Included Systematic Reviews by Intervention ( $n=11$ Reviews)

\begin{tabular}{|c|c|}
\hline Intervention & Included Systematic Reviews (Reference) \\
\hline $\begin{array}{l}\text { Dissemination of } \\
\text { educational materials/ } \\
\text { clinical practice guidelines }\end{array}$ & $\begin{array}{l}\text { Davis et al., } 1995(11)^{*} \\
\text { Hulscher et al., } 2002(13)^{*} \\
\text { Thomas et al., } 2002(14) \\
\text { Wensing et al., } 1998(12)^{*}\end{array}$ \\
\hline $\begin{array}{l}\text { Formal continuing medical } \\
\text { education }\end{array}$ & $\begin{array}{l}\text { Davis et al., } 1995(11)^{*} \\
\text { Harvey et al } 2002(16) \\
\text { Hulscher et al., } 2002(13)^{*} \\
\text { Thomson O'Brien et al., } 2002(15)\end{array}$ \\
\hline $\begin{array}{l}\text { Educational outreach } \\
\text { (academic detailing) }\end{array}$ & $\begin{array}{l}\text { Oxman et al., } 1995(9)^{*} \\
\text { Thomson O'Brien et al., } 2002(17)\end{array}$ \\
\hline $\begin{array}{l}\text { Local opinion leaders } \\
\text { (social influence) }\end{array}$ & $\begin{array}{l}\text { Hulscher et al., } 2002(13)^{*} \\
\text { Thomson O'Brien et al., } 2002(18) \\
\text { Wensing et al., } 1998(12)^{*}\end{array}$ \\
\hline Reminders & $\begin{array}{l}\text { Davis et al., } 1995(11)^{*} \\
\text { Hulscher et al., } 2002(13)^{*} \\
\text { Mandelblatt and Kanetsky, } 1995(19) \\
\text { Snell and Buck, } 1996(20)\end{array}$ \\
\hline
\end{tabular}

* Studies appeared multiple times because they included more than one intervention.

TABLE 2

List of Excluded Studies $(n=13)$

\begin{tabular}{|c|c|}
\hline Exluded Study (Reference) & Reasons for Exclusion \\
\hline Beaudry, 1989 (27) & $\begin{array}{l}\text { Efficacy of single interventions was not } \\
\text { assessable }\end{array}$ \\
\hline Beilby et al., 1997 (28) & $\begin{array}{l}\text { Outcome not relevant- change in prescription } \\
\text { behavior/costs reduction }\end{array}$ \\
\hline Davis, 1998 (29) & Overlap with newer publication \\
\hline $\begin{array}{l}\text { Davis \& Taylor-Vaisey, } \\
1997(26)\end{array}$ & Overlap with newer publication \\
\hline Davis et al., 1992 (30) & $\begin{array}{l}\text { Efficacy of single interventions was not } \\
\text { assessable }\end{array}$ \\
\hline Figueiras et al., 2001(31) & $\begin{array}{l}\text { Efficacy of single interventions was not } \\
\text { assessable }\end{array}$ \\
\hline Freemantle et al., 2000 (32) & Withdrawn from the Cochrane Library \\
\hline Grimshaw \& Russell, 1993 (33) & $\begin{array}{l}\text { Efficacy of single interventions was not } \\
\text { assessable }\end{array}$ \\
\hline Hulscher et al., 1999 (34) & Overlap with newer publication \\
\hline Lancaster et al., 2002 (35) & $\begin{array}{l}\text { Efficacy of single interventions was not } \\
\text { assessable }\end{array}$ \\
\hline Waddell, $1991(36)$ & $\begin{array}{l}\text { Efficacy of single interventions was not } \\
\text { assessable }\end{array}$ \\
\hline Worrall et al., 1997 (37) & $\begin{array}{l}\text { Outcome not relevant-only patient outcome } \\
\text { measured }\end{array}$ \\
\hline Yano et al., 1995 (38) & $\begin{array}{l}\text { Efficacy of single interventions was not } \\
\text { assessable }\end{array}$ \\
\hline
\end{tabular}

tional materials such as printed monographs or audiovisual programs with no intervention control failed to dem- onstrate a positive effect on professional performance or patient outcomes. Wensing et al. (12) reported 
TABLE 3

Quality Assessment for Systematic Reviews Included

\begin{tabular}{|c|c|c|}
\hline Author (Reference) & Database Searched & Level of Flaws* \\
\hline Davis et al., 1995 (11) & MEDLINE, ERIC, NTIS, and other data sources (1975-94) & Minor \\
\hline Harvey et al., 2001 (16) & $\begin{array}{l}\text { Cochrane Effective Practice and Organization of care group and others } \\
(1997-2000) \text {. MEDLINE, EMBASE, Cinahl, and others }(1973-2000)\end{array}$ & Minor \\
\hline Hulscher et al., 2002 (13) & EPOC, MEDLINE, CINAHL (up to 2001) & Minor \\
\hline Mandelblatt et al., 1995 (19) & MEDLINE (1980-93) & Minimal \\
\hline Oxman et al., 1995 (9) & MEDLINE, SCISEARCH, CINAHL and others (1970-93) & Minor \\
\hline Thomas et al., 2002 (14) & $\begin{array}{l}\text { MEDLINE, CINAHL, Psyclit, EMBASE, NHS Economic Evaluations } \\
\text { Database; DHSS-Data and DARE (1975-76) }\end{array}$ & Minor \\
\hline Thomson O'Brien et al., 2002 (15) & EPOC, RBRD/CME MEDLINE (1966-99) & Minor \\
\hline Thomson O'Brien et al., 2002(17) & MEDLINE (up to March 1997), RBRD/CME and others & Minimal \\
\hline Thomson O'Brien et al., 2002 (18) & MEDLINE (up to May 1998), RBRD/CME and others & Minimal \\
\hline Snell et al., $1996(20)$ & National Library of Medicine (MESH 1989-94) & Minimal \\
\hline Wensing et al., $1998(12)$ & MEDLINE (1980-94) & Minor \\
\hline
\end{tabular}

"Level of flaws is based on 17 items of the Quorum checklist: (1) minimal flaws (15 or more items fulfilled), (2) minor flaws (13-14 items fulfilled), (3) major flaws (11-12 items fulfilled), and (4) extensive flaws (10 or fewer items fulfilled).

that information transfer through dissemination of educational materials showed no effect in nine out of 17 studies. Hulscher et al. (13) reviewed three studies and reported that two studies showed positive effects and one study found no differences. None of these reviews specifically described the target behaviors and the contents of disseminated information. There was one review that specifically compared disseminating clinical guidelines versus control (14). This review reported that three out of five studies showed significant improvements in clinical management by disseminating clinical guidelines.

Overall, evidence from systematic reviews on efficacy of disseminating educational materials was inconclusive. Clinical guidelines may have a positive effect on practice behaviors of primary care providers; however, there is no information to draw conclusions on which behaviors it might suit better. None of the reviews provided either the details in outcomes or statistical significance of the results.

Formal Continuing Medical Education. This group of educational interventions covered a wide range of activities including lectures, workshops, educational meetings, and group trainings. The efficacy of continuing medical education was assessed on a broad range of outcomes (e.g., clinical management, prescribing, prescribing counseling, and preventive procedures).
Four reviews that evaluated the impact of formal continuing medical education on primary care providers' practice behaviors met the inclusion criteria. Davis et al. (11) reported that the majority (six out of seven) of the studies focusing on continuing medical education provided in a short session showed no change or inconclusive results on primary care providers' behaviors. This review, however, did not describe in detail for which specific type of outcomes these interventions were efficacious or not. Thomson$\mathrm{O}^{\prime}$ Brien et al. (15) reported that six out of seven studies using didactic presentations did not improve primary care provider's behaviors, whereas seven out of eight studies with interactive workshops produced significant improvements in professional behaviors. A review by Hulscher et al. (13) reported that four out of five studies with small group education (seminar, workshop, and educational meeting) showed improvements (relative differences ranged from -11 percent to $194 \%$ ) on preventive care in a primary care setting. This review also pointed that the largest difference was found in small group discussion and teleconference targeting hypertension monitoring or colorectal cancer screening. Another review by Harvey et al. (16) also reported positive changes in two studies out of three, at least for short term, in primary care providers' obesity management after a brief medical education session. However, the authors pointed out that the results were neither conclusive nor generalizable due to overall poor quality of included studies.

Drawing conclusions from the four included reviews was not easy, because the reviews dealt with a broad range of outcomes and there were substantial differences in focus, design, and reporting. Nevertheless, one common message that could be summarized from these reviews was that the dissemination of information through traditional continuing medical education methods such as lectures or workshops did not effectively change primary care providers' behavior. It was indicated that some forms of continuing medical education such as small, more targeted, interactive group discussion and teleconferencing sessions might be more efficacious.

Educational Outreach Visits (Academic Detailing). We located two systematic reviews of educational outreach visits. Oxman and colleagues (9) reported results from seven out of eight studies on educational outreach and concluded that outreach visits were effective in reducing inappropriate prescribing and delivery of preventive procedures. The results showed that there were reduction of 12 percent to 49 percent in inappropriate prescription from 4 studies and 5 percent to 27 percent increase in adoption of preventive practices including smoking cessation from two studies. (One study was a report of outreach 
TABLE 4 [cont $p$ 169]

Summary of Included Reviews on Specific Interventions (Single Intervention vs No Intervention)

\begin{tabular}{|c|c|c|c|c|}
\hline Author/Year & $\begin{array}{l}\text { Total No. of } \\
\text { Included } \\
\text { Studies (Design) }\end{array}$ & $\begin{array}{l}\text { Characteristics of } \\
\text { Specific Comparison }\end{array}$ & Results & Authors' Conclusion (Remarks) \\
\hline \multicolumn{5}{|c|}{ Educaftonal materials } \\
\hline $\begin{array}{l}\text { Davis et al., } 1995 \\
(11)^{*}\end{array}$ & $\begin{array}{l}99 \text { studies (RCT, } \\
\mathrm{CCT})\end{array}$ & $\begin{array}{l}11 \text { studies included } \\
\text { educaiton materials vs no } \\
\text { intervention }\end{array}$ & $\begin{array}{l}4 \text { out of } 11 \text { studies showed } \\
\text { improvement, but } 7 \text { did not. No } \\
\text { description of outcome } \\
\text { measurements. }\end{array}$ & $\begin{array}{l}\text { No intervention-specific conclusion } \\
\text { provided. }\end{array}$ \\
\hline $\begin{array}{l}\text { Hulscher et al., } \\
2002(13)^{*}\end{array}$ & $\begin{array}{l}55 \text { studies ( } 37 \\
\text { RCT, } 18 \text { CCT) }\end{array}$ & $\begin{array}{l}3 \text { studies regarding } \\
\text { educational materials vs } \\
\text { no intervention }\end{array}$ & $\begin{array}{l}2 \text { out of } 3 \text { studies reported } \\
\text { improvement in the intervention } \\
\text { group. No further details were } \\
\text { described. }\end{array}$ & $\begin{array}{l}\text { No specific conclusion for this } \\
\text { intervention provided. }\end{array}$ \\
\hline $\begin{array}{l}\text { Thomas et al., } \\
2002 \text { (14) }\end{array}$ & $\begin{array}{l}18 \text { studies (13 } \\
\text { RCT, } 2 \text { CBA, } 3 \text { ITS) }\end{array}$ & $\begin{array}{l}5 \text { studies compared } \\
\text { guidelines vs no } \\
\text { guideline control }\end{array}$ & $\begin{array}{l}3 \text { out of } 5 \text { studies that compared } \\
\text { clinical guidelines vs no guidelines } \\
\text { showed significant improvement in } \\
\text { clinical management by professions } \\
\text { allied to medicine (mainly nurses). }\end{array}$ & $\begin{array}{l}\text { Findings provide some evidence } \\
\text { that guideline-driven care can be } \\
\text { effective in changing the process } \\
\text { and outcome of care provided by } \\
\text { professions allied to medicine. }\end{array}$ \\
\hline $\begin{array}{l}\text { Wensing et al., } \\
1998(12)^{*}\end{array}$ & $\begin{array}{l}61 \text { studies ( } 39 \\
\text { RCTs and } 22 \\
\text { CBAs) }\end{array}$ & $\begin{array}{l}17 \text { comparisons } \\
\text { information transfer vs } \\
\text { no intervention }\end{array}$ & $\begin{array}{l}9 \text { out of } 17 \text { comparisons showed no } \\
\text { improvements, } 6 \text { were partially } \\
\text { efficacious, and only } 2 \text { showed } \\
\text { efficacy. Efficacy on preventive } \\
\text { practices was not separately } \\
\text { assessable. }\end{array}$ & $\begin{array}{l}\text { Information transfer is probably } \\
\text { always needed, but more } \\
\text { interventions are usually needed to } \\
\text { achieve real changes in the practice } \\
\text { routines of clinicians. }\end{array}$ \\
\hline \multicolumn{5}{|c|}{ Formal CME (conferenced educational meetings) } \\
\hline $\begin{array}{l}\text { Davis et al., } 1995 \\
(11)^{*}\end{array}$ & $\begin{array}{l}99 \text { studies (RCT, } \\
\mathrm{CCT})\end{array}$ & $\begin{array}{l}7 \text { studies included } \\
\text { conference vs no } \\
\text { intervention }\end{array}$ & $\begin{array}{l}\text { Formal CME conferences ( } 6 \text { out of } 7 \\
\text { studies) showed negative or } \\
\text { inconclusive results. No description } \\
\text { of outcome measurements. }\end{array}$ & $\begin{array}{l}\text { Widely used CME delivery methods } \\
\text { such as conferences have little direct } \\
\text { impact on improving professional } \\
\text { practice. }\end{array}$ \\
\hline $\begin{array}{l}\text { Harvey et al } 2002 \\
(16)^{*}\end{array}$ & $\begin{array}{l}18 \text { studies (RT, } \\
\text { CBA, Time series } \\
\text { analysis) }\end{array}$ & $\begin{array}{l}3 \text { studies included brief } \\
\text { educational session vs no } \\
\text { intervention }\end{array}$ & $\begin{array}{l}2 \text { studies suggest positive change in } \\
\text { professionals' behavior of obesity } \\
\text { management in the short-term } \\
\text { period. Results of the other study } \\
\text { were not conclusive because of } \\
\text { overall poor quality methodology. }\end{array}$ & $\begin{array}{l}\text { Brief educational intervention on } \\
\text { obesity management may be } \\
\text { effective in changing practice. More } \\
\text { rigorous evaluations are necessary } \\
\text { to determine whether these changes } \\
\text { are generalizable. }\end{array}$ \\
\hline $\begin{array}{l}\text { Hulscher et al., } \\
2002(13)^{*}\end{array}$ & $\begin{array}{l}55 \text { studies (37 } \\
\text { RCT, } 18 \text { CCT) }\end{array}$ & $\begin{array}{l}5 \text { comparisons regarding } \\
\text { educational conference } \\
\text { vs. no intervention }\end{array}$ & $\begin{array}{l}4 \text { out of } 5 \text { comparisons showed } \\
\text { outcome favorable to intervention } \\
\text { group. The largest difference was } \\
\text { found in small group discussion } \\
\text { and teleconference. }\end{array}$ & $\begin{array}{l}\text { No intervention-specific conclusion } \\
\text { provided. }\end{array}$ \\
\hline $\begin{array}{l}\text { Thomson } O^{\prime} \text { Brien } \\
\text { et al., } 2002(15)\end{array}$ & $\begin{array}{l}32 \text { studies ( } 30 \\
\text { RCTs, } 2 \text { NEGDs) }\end{array}$ & $\begin{array}{l}\text { Continuing education } \\
\text { meetings and workshops } \\
\text { vs no intervention }\end{array}$ & $\begin{array}{l}6 \text { of } 7 \text { studies with lectures or } \\
\text { didactic presentations showed no } \\
\text { improvements. } 7 \text { of } 8 \text { studies with } \\
\text { interactive workshops showed } \\
\text { significant improvements. }\end{array}$ & $\begin{array}{l}\text { Interactive workshops can improve } \\
\text { professional practice. Lectures } \\
\text { (didactic sessions) alone are unlikely } \\
\text { to change professional practice. }\end{array}$ \\
\hline \multicolumn{5}{|c|}{ Educational outreach visits (academic detailing) } \\
\hline $\begin{array}{l}\text { Oxman et al., } 1995 \\
(9)^{*}\end{array}$ & 102 trials & $\begin{array}{l}7 \text { studies compared } \\
\text { educational outreach vs } \\
\text { no intervention }\end{array}$ & $\begin{array}{l}4 \text { studies showed } 12-49 \text { percent } \\
\text { reduction in inappropriate } \\
\text { prescribing and } 3 \text { studies showed } \\
\text { improvements in preventive } \\
\text { practices (including smoking } \\
\text { cessation and } 10 \text { other preventive } \\
\text { practices). }\end{array}$ & $\begin{array}{l}\text { Outreach visits were effective in } \\
\text { (reducing inappropriate prescribing } \\
\text { and) increasing the delivery of } \\
\text { preventive services. }\end{array}$ \\
\hline $\begin{array}{l}\text { Thomson O'Brien } \\
\text { et al., } 2002 \text { (17) }\end{array}$ & 18 RCTs & $\begin{array}{l}3 \text { trials compared } \\
\text { outreach visits with no } \\
\text { intervention. }\end{array}$ & $\begin{array}{l}3 \text { trials of outreach visits alone vs no } \\
\text { intervention showed } 24 \text { percent to } \\
50 \text { percent relative improvements in } \\
\text { appropriate prescribing practices. }\end{array}$ & $\begin{array}{l}\text { Educational outreach visits, } \\
\text { particularly when combined with } \\
\text { social marketing, appear to be a } \\
\text { promising approach to modifying } \\
\text { health professional behavior, } \\
\text { especially prescribing. }\end{array}$ \\
\hline
\end{tabular}

visits with other interventions.) Thompson-O'Brien and colleagues (17) reported 24 percent to 50 percent relative improvements in appropriate prescribing practices from the results of three trials that compared outreach visits with no intervention.

Educational outreach visits or academic detailing has been widely used 
TABLE 4 [cont from $p$ 168]

Summary of Included Reviews on Specific Interventions (Single Intervention vs No Intervention)

\begin{tabular}{llll} 
& $\begin{array}{l}\text { Total No. of } \\
\text { Included } \\
\text { Author/Year }\end{array}$ & Studies (Design) & Characteristics of \\
Specific Comparison & Results & Authors' Conclusion (Remarks) \\
\hline
\end{tabular}

\section{Local opinion leaders}

Hulscher et al., 55 studies (37 $2002(13)^{*} \quad$ RCT, 18 CCT $)$

Thomson O'Brien 8 RCTs et al., 2002 (18)

Wensing et al. $1998(12)^{*}$

61 studies $(39$ RCTs and 22 CBAs)

7 comparisons for social influence as intervention

6 trials compared the local opinion leaders vs no intervention

1 comparison regarding social influence vs no intervention

An individual tutorial session from a local opinion leader showed 187.2 percent relative increase $(44 \%$ absolute increase) in preventive services

5 out of 6 trials showed improvements in clinical management regarding specific patient problems. Only one study showed strong evidence of efficacy with statistical significance.

2 showed efficacy, 3 showed partial efficacy and 2 showed no efficacy. Efficacy of social influence on preventive practices was not separately reported.

\section{Reminders} reminders as single
Davis et al. 1995

$(11)^{*}$

99 studies (RCT, CCT)

26 studies compared intervention

Hulscher et al., 55 studies ( 37 $2002(13)^{*} \quad$ RCT, 18 CCT)

Mandelblatt and 20 trials (9 CT, 11 Kanetsky, 1995 (19) RT)

9 RCTs compared physician reminders vs control

6 trials included noncomputerized physician reminders

14 comparisons included manual reminders

\section{Physician reminders showed} positive changes (22 out of 26 studies). Outcome measures were not specified.

9 studies showed improvement in the intervention group ( $13 \%$ to $264 \%$ provided.

relative change) in preventive services.

5 out of 6 trials showed improvement in using mammography or clinical breast exam for cancer screening ( 8 to $28 \%$ increase). One study showed

decrease $(-24 \%)$.

Snell and Buck, $\quad 38$ studies $1996(20)$ provided.
Meta-analysis showed effect size of 0.21 showing increase in cancer screening by reminders targeting physicians compared to control.
No intervention-specific conclusion provided.

Using local opinion leaders results in mixed effects on professional practice change. It is not clear what local opinion leaders do and in which circumstances they are likely to influence the practice.

No intervention-specific conclusion provided.

Physician reminder was an effective single-method intervention.

No intervention-specific conclusion Physician-based interventions (reminders) can be effective in increasing screening use.

No intervention-specific conclusion

\footnotetext{
*Studies appeared multiple times because they included more than one intervention methods. Acronyms in primary study design: RCT-randomized controlled trial, CCT-controlled clinical trial, ITS-interrupted time series, CBA-controlled before-and-after studies, NEGD-nonequivalent group design (nonrandom controlled trials).
}

by pharmaceutical companies in marketing. However, there is paucity of reports about its efficacy in adoption of preventive practices. Given the limitation of small number of studies, the summary from the two systematic reviews indicated that educational outreach visits were effective in increasing the delivery of preventive services, as well as in reducing inappropriate prescribing practices.

Local Opinion Leaders. We located three systematic reviews that specifically focused on the influence of local opinion leaders on the change in primary care providers' behavior. The first review (18) included eight ran- domized trials that compared local opinion leaders to no intervention and reported absolute risk reductions ranging from 0.11 to 0.30 in managing various medical problems such as acute myocardial infarction, cancer pain, and osteoarthritis among others. Since the target outcome was clinical management of various medical problems, the efficacy on adoption of preventive procedures was not described. The second review showed 44 percent absolute increase in delivery of preventive services such as dietary counseling and hypertension monitoring (13). No further details including statistical significance were reported. The third review reported that five out of seven studies showed some improvements on outcomes such as recording routines or consultation skills, when local opinion leaders were used (12). This review, however, did not provide details with regard to characteristics of primary studies such as target behaviors and outcome measures.

It was not clear from these reviews whether interventions relying on local opinion leaders were efficacious in changing primary care providers' behaviors, especially regarding preventive procedures. Also, as pointed out in a review (18), there is not enough information to clarify for which target 
behaviors and in which circumstances the local opinion leaders are likely to influence the practice of their peers.

Reminders. Reminders can be manual or computerized. We focused only on manual reminders in our overview due to feasibility of application in dental public health programs. Reviews that focused only on computerized reminder system were excluded in this overview (Table 2). We located four systematic reviews of reminder. Davis et al. (11) reported reminders showed improvements in professional behavior in 22 out of 26 studies in their review. Hulscher et al. (13) reported 13 percent to 264 percent relative improvements in preventive services by reminders from the results of nine studies. In these reviews, there was no further detailed information on the nature of the intervention (e.g., manual or computerized) and target behaviors. Mandelblatt and Kanetsky (19) reported an increase in breast cancer screening from 6 percent to 28 percent from the results of five out of six studies of manual reminders. The authors reported the results of manual reminders and computerized reminders were similar in magnitude. Snell and Buck (20) reported increase (effect size $\mathrm{d}=0.21$ ) in cancer screening frequency from a meta-analysis of 14 comparisons of manual-reminder-targeted physicians.

Overall, there are consistent findings among the four systematic reviews (including one meta-analysis) showing that manual reminders are efficacious in promoting primary care providers to adopt preventive practices. While no study has reported efficacy of reminders on adopting oral health screening by primary care providers, this would be one method that can be used by dental public health professionals to promote oral health screening in the primary health care setting.

\section{Discussion}

Modifying primary care providers' practice behavior to adopt new procedures or guidelines in their practice is a challenging task $(9,11)$. In this overview, 12 systematic reviews that focused on efficacy of single interventions on changes in professional behaviors of health care providers were evaluated. The evidence from the included systematic reviews showed that disseminating printed educa- tional materials and traditional (didactic) continuing medical education in a large group setting did not effectively change primary care providers' behaviors. There are effective interventions available to increase knowledge and change behaviors of primary care providers, such as group discussion, interactive workshops, educational outreach visits, and reminders. The findings of this overview that focused on single educational interventions generally agree with the conclusions from previous overviews $(21,22)$ focusing on multiple educational interventions. Information on the efficacy of single interventions may be more appropriate and single interventions are less costly for dental public health programs that plan to design educational interventions to change the practice of primary care providers.

Caution is needed when the results of this overview are applied to a specific behavior or a target group. The majority of the reviews included in this overview did not have conclusive findings regarding the efficacy of single interventions on primary care providers' practice behaviors. Only one review reported results from meta-analysis. All other reviews described the results qualitatively or quantitatively without being able to synthesize the results. Although the body of the research focusing on the efficacy of interventions to improve primary care providers' behavior is relatively large, the knowledge base is clearly limited when specific behaviors and interventions are considered. There was large heterogeneity among primary trials in each systematic review. Most systematic reviews also pointed to the paucity of good quality primary studies: reporting quality of primary studies in general was poor, specifically regarding randomization, blinding, and unit of analysis.

Given the difficulties of each systematic review due to heterogeneity and the low quality of primary trials, summarizing results from systematic reviews imposes more difficulties in drawing conclusive findings for a specific intervention. There was wide variation among the reviews regarding the interventions, target outcomes, and comparison groups. Therefore, $\mathrm{di}$ rect comparison among systematic reviews was not feasible.

In this overview, we included results only from systematic reviews that were published in English. Possibly trials that failed to detect a significant impact of a given intervention were less likely to be included in a systematic review than those reporting positive findings, which are more likely to be published (i.e., publication bias). Some primary studies were included in more than one systematic review. The extent to which the multiple inclusions of the same study in multiple reviews could affect the conclusions of this overview cannot be assessed.

We did not include reviews on interventions that aimed only at patients or at organization level because our main interest was the efficacy of interventions targeting primary care providers that can be implemented without significant cost or administrative changes. Obviously, other factors beyond individual knowledge and attitude influence primary care providers' practice behaviors (23). Other barriers to behavior change might include an inadequate practice organization, lack of time, negative financial incentives, negative attitudes among colleagues, or resistance from patients (12). The primary interest of this overview was to evaluate interventions to improve the primary care provider's knowledge and adoption of oral health screening, referral, and prevention. However, our overview yielded neither directly relevant systematic reviews nor well-designed randomized clinical trials focusing on this topic.

Changing primary care providers' behavior, especially to incorporate oral health screening, requires more than just selecting and implementing one or more efficacious interventions. To be successful, barriers that exist in specific contexts should be identified and addressed. A major barrier is lack of knowledge on oral health $(7,24)$. Currently, there is little information and guidelines available to primary care providers on prevention of oral diseases and oral health promotion (7). It is necessary to develop well-designed educational information and guidelines targeting primary care providers. One nationwide survey showed that pediatricians are more likely to follow clinical practice guidelines if they were simple to follow, feasible/practical, and effective (25). However, as already indicated, dissemination-only activities would incur little behavioral change. It should 
be augmented by other interventions, such as reminders.

Changing primary care providers' behavior should be approached in a comprehensive and contextual manner considering the large social and political forces such as group norms professional regulations, and environmental considerations that include practice location, demographics, setting, and patient issues (26). Selection and application of interventions should be carefully tailored by the characteristics of providers, patients, and practice-related factors in a specific context. Dental professionals who plan to design and implement educational interventions should use focus groups to define the context specific to their communities.

This overview provides a synopsis on interventions to improve primary care providers' practice behaviors. While there has been a growing interest in research of educational interventions targeting primary care providers, the knowledge base on the efficacy of various interventions for different outcomes in primary care setting is limited; there is virtually no information on the efficacy of these interventions on oral health screening by primary care providers. Considering the strategic position of primary care providers in improving oral health of underserved population, this area deserves much greater attention and research.

\section{References}

1. US Department of Health and Human Services, Oral Health in America: a report of the surgeon general. Rockville, MD: US Department of Health and Human Services, National Institute of Dental and Craniofacial Research, National Institutes of Health, 2000; NIH pub no 00-4713.

2. Vargas CM, Crall J], Schneider DA. Sociodemographic distribution of pediatric dental caries: NHANES III, 1988-1994. I Am Dent Assoc 1998;129:1229-38.

3. Mouradian WE, Wehr E, Crall J. Disparities in children's oral health and access to dental care. JAMA 2000;284:2625-31.

4. Vargas CM, Ronzio CR, Relationship between children's dental needs and dental care utilization: United States, 1988-1994. Am J Public Health 2002;92:1816-21.

5. US Department of Health and Human Services. Children's dental services under Medicaid: access and utilization. Washington, DC: US Department of Health and Human Services, Office of Inspector General, 1996; rep no OEI-0900240.

6. Guiden M. Dental health for kids moves to the forefront. In: National Conference of State Legislatures. Forum for State Health Policy Leadership. State Health Notes 1998;19(280).

7. Lewis CW, Grossman DC, Domoto PK, Deyo RA. The role of the pediatrician in the oral health of children: a national survey. Pediatrics 2000;106(6):E84. Available from: http://www.pediatrics.org/ cgi/content/full/106/6/e84.

8. Mouradian WE. The face of a child: children's oral health and dental education. J Dent Educ 2001;65:821-31.

9. Oxman AD, Thomson MA, Davis DA, Haynes RB. No magic bullets: a systematic review of 102 trials of interventions to improve professional practice. CMAJ 1995;153:1423-31.

10. Moher D, Cook DJ, Eastwood S, Olkin I, Rennie D, Stroup DF. Improving the quality of reports of meta-analyses of randomised controlled trials: the QUOROM statement. Lancet 1999;354: 1896-900.

11. Davis DA, Thomson MA, Oxman AD, Haynes RB. Changing physician performance. A systematic review of the effect of continuing medical education strategies. JAMA 1995;274:700-5.

12. Wensing $M$, van der Weijden $T$, Grol $R$. Implementing guidelines and innovations in general practice: which interventions are effective? Br J Gen Pract 1998; 48:991-7.

13. Hulscher ME, Wensing $M$, van der Weijden $T$, Grol R. Interventions to implement prevention in primary care (COchrane Review). In: The Cochrane Library. Chichester, UK: John Wiley \& Sons, Ltd., 2002; Iss 4

14. Thomas L, Cullum N, McColl E, Rousseau N, Soutter J, Steen N. Guidelines in professions allied to medicine (Cochrane Review). In: The Cochrane Library. Chichester, UK: John Wiley \& Sons, I.td., 2002 , Iss 4.

15. Thomson $O^{\prime}$ Brien MA, Freemantle $N$, Oxman AD, Wolf F, Davis DA, Herrin J. Continuing education meetings and workshops: effects on professional practice and health care outcomes (Cochrane Review). In: The Cochrane Library. Chichester, UK: John Wiley \& Sons, Ltd., 2002, Iss 2.

16. Harvey EL, Glenny AM, Kirk SF, Summerbell $C D$. Improving health professionals' management and the organisation of care for overweight and obese people (Cochrane Review). In: Cochrane Library. Chichester, UK: John Wiley \& Sons, Ltd., 2002, Iss 4.

17. Thomson $O^{\prime} B$ rien MA, Oxman $A D$, Davis DA, Haynes RB, Freemantle N, Harvey EL. Educational outreach visits: effects on professional practice and health care outcomes (Cochrane Review). In: Cochrane Library. Chichester, UK: John Wiley \& Sons, Ltd, 2002, Iss 4.

18. Thomson $O^{\prime}$ Brien MA, Oxman AD, Haynes RB, Davis DA, Freemantle N, Harvey EL. Local opinion leaders: effects on professional practice and health care outcomes (Cochrane Review). In: Cochrane Library. Chichester, UK: John Wiley \& Sons, Ltd., 2002, Iss 4.

19. Mandelblatt J, Kanetsky PA. Effectiveness of interventions to enhance physician screening for breast cancer. J Fam
Pract 1995:40:162-71.

20. Snell JL, Buck EL. Increasing cancer screening: a meta-analysis. Prev Med 1996;25:702-7.

21. Bero LA, Grilli R, Grimshaw J, Harvey EL, Oxman AD, Thomson O'Brien MA. Closing the gap between research and practice: an overview of systematic reviews of interventions to promote the implementation of research findings. The Conchrane Effective Practice and Organization of Care Review Group. BM] 1998;317:465-8.

22. NHS Center for Reviews and Dissemination. Getting evidence into practice. Effective Health Care 1999;5:1-16.

23. Landon BE, Reschovsky J, Reed M, Blumenthal D. Personal, organizational, and market level influence on physicians' practice patterns. Med Care 2001; 39:889-905.

24. Siriphant P, Horowitz AM, Child WL. Perspectives of Maryland adult and family practice nurse practitioners on oral cancer. J Public Health Dent 2001;61:1459.

25. Flores G, Lee M, Bauchner H, Kastner B. Pediatricians' attitudes, beliefs, and practices regarding clinical practice guidelines: a national survey. Pediatrics 2000 105:496-501

26. Davis DA, Taylor-Vaisey A. Translating guidelines into practice. A systematic review of theoretic concepts, practical experience and research evidence in the adoption of clinical practice guidelines. CMAJ 1997;157:408-16.

27. Beaudry JS. The effectiveness of continuing medical education: a quantitative synthesis. J Contin Educ Health Prof 1989,9:285-307.

28. Beilby JJ, Silagy CA. Trials of providing costing information to general practitioners: a systematic review. Med J Aust 1997;167:89-92.

29. Davis D. Does CME work? An analysis of the effect of educational activities on physician performance or health care outcomes. Int J Psych Med 1998;28:21-39.

30. Davis $D$, Thompson MA, Oxman AD, Haynes B. Evidence for the effectiveness of CME. A review of 50 randomized controlled trials. JAMA 1992;268:1111-17.

31. Figueiras A, Sastre I, Gestal-Otero JJ. Effectiveness of educational interventions on the improvement of drug prescription in primary care: a critical review. J Eval Clin Pract 2001;7:223-41.

32. Freemantle N, Harvey EL, Wolf F, Grimshaw JM, Grilli R, Bero LA. Printed educational materiais: effects on professional practice and health care outcomes ( $\mathrm{Co}$ chrane Review). In: Cochrane Library. Chichester, UK: John Wiley \& Sons, Ltd., 2002, Iss 2. (Withdrawn from the Cochrane library.)

33. Grimshaw JM, Russell IT. Effect of clinical guidelines on medical practice: a systematic review of rigorous evaluations. Lancet 1993;342:1317-22.

34. Hulscher MEIL, Wensing M, Grol R, van der Weijden $T$, Van Weel $C$. Interventions to improve the delivery of prevention services in primary care. Am J Public Health 1999;89:737-46.

35. Lancaster T, Silagy CA, Fowler G. Training health professionals in smoking ces- 
sation (Cochrane Review). In: Cochrane Library. Chichester, UK: John Wiley \& Sons, Ltd., 2002, Iss 4.

36. Waddell DL. The effects of continuing education on nursing practice: A meta- analysis. J Continuing Educ Nursing 1991;22:113-18.

37. Worrall G, Chaulk P, Freake D. The effects of clinical practice guidelines on patient outcomes in primary care: a systematic review. CMAJ 1997;156:1705-12.
38. Yano EM, Fink A, Hirsch SH, Robins AS, Rubenstein LV. Helping practices reach primary care goals: Lessons from the literature. Arch Intern Med 1995;155:114656. 